\title{
Karl Löwith
}

Der Mensch inmitten der Geschichte 


\section{Karl Löwith \\ Der Mensch inmitten der Geschichte}

Philosophische Bilanz des 20. Jahrhunderts

Herausgegeben von Bernd Lutz

J. B. Metzlersche Verlagsbuchhandlung Stuttgart 
CIP-Titelaufnahme der Deutschen Bibliothek

Löwith, Karl:

Der Mensch inmitten der Geschichte: philosophische Bilanz des 20. Jahrhunderts/

Karl Löwith. Hrsg. von Bernd Lutz. -

Stuttgart : Metzler, 1990

ISBN 978-3-476-00713-1

ISBN 978-3-476-03324-6 (eBook)

DOI 10.1007/978-3-476-03324-6

Dieses Werk einschließlich aller seiner Teile ist urheberrechtlich geschützt. Jede Verwertung außerhalb der engen Grenzen des Urheberrechtsgesetzes ist ohne Zustimmung des Verlages unzulässig und strafbar. Das gilt insbesondere für Vervielfältigungen, Übersetzungen, Mikroverfilmungen und die Einspeicherung und Verarbeitung in elektronischen Systemen.

(C) 1990 Springer-Verlag GmbH Deutschland

Ursprünglich erschienen bei J. B. Metzlersche Verlagsbuchhandlung und Carl Ernst Poeschel Verlag GmbH in Stuttgart 1990 


\section{Inhalt}

1932 Existenzphilosophie .................. 1

1935 Politischer Dezisionismus (C. Schmitt)........... 19

1940 Der europäische Nihilismus. Betrachtungen zur geistigen Vorgeschichte des europäischen Krieges .......... 49

1950 Weltgeschichte und Heilsgeschehen ........... 115

1950 Natur und Geschichte ................. 155

1957 Natur und Humanität des Menschen ........... 171

1958 Marxismus und Geschichte . . . . . . . . . . . 207

1960 Mensch und Geschichte .................. 223

1960 Bemerkungen zum Unterschied von Orient und Okzident 254

1960 Nietzsche nach sechzig Jahren............... 285

1961 Vom Sinn der Geschichte ................ 305

1963 Das Verhängnis des Fortschritts . . . . . . . . . 320

1966 Christentum, Geschichte und Philosophie ......... 339

$1969 \mathrm{Zu}$ Heideggers Seinsfrage: Die Natur des Menschen und die Welt der Natur ................. 358

1970 Wahrheit und Geschichtlichkeit ............ 372

Nachwort .......................... 385 